\title{
Is Current Research Assisting The Implementation of Contemporary ICT in the Primary Mathematics Classroom?
}

\author{
Catherine Attard \\ Centre for Educational Research \\ Western Sydney University, Australia
}

\begin{abstract}
The fast pace of development of ICT often results in primary teachers being expected to integrate new technologies effectively prior to the emergence of research findings that provide exemplars of best practice. This discussion paper explores contemporary research into ICT and primary school mathematics, and the issues that arise in relation to mobile technologies such as computer tablets in primary school classrooms. Although studies are beginning to emerge, this paper presents the argument that further research that would assist teachers in being prepared to teach mathematics with any technological tool would be more beneficial than working retrospectively to explore the use of specific devices that have already emerged in primary classrooms.
\end{abstract}

Keywords: ICT, primary school, technology, best practice, Tablet, TPACK, SAMR

\section{Introduction}

The rapid pace of development of information and communication technologies (ICT) has resulted in the expectation that teachers are able to effectively implement new ICT devices into the teaching and learning of mathematics as soon as they appear in classrooms. Often this occurs with very little support in the way of professional development and the provision of best practice exemplars or effective theoretical frameworks that teachers can easily apply to their practice. Educators often make the assumption that the use of technology is going to result in increased student engagement and improved academic outcomes. We also make assumptions about the teacher's affinity with technology (Orlando \& Attard, 2015). Do our young teachers, the 'digital natives' (Prensky, 2001), have the ability to integrate technology effectively simply because they have grown up with technology?

This paper presents a discussion that explores a range of current research into teaching and learning with technology in the primary mathematics classroom, using the recent trend towards the use of computer tablets as an illustration. Although there are many aspects of technology integration and related issues, due to the limitations of this paper a select few will be discussed. First, a short overview of some of the recent topics of research into tablet technology and mathematics is provided. This will be followed by a brief review of frameworks relating to technology integration and a discussion relating to student engagement and the use 
of mobile technologies in mathematics classrooms. Finally, suggestions for possible future research directions that will assist primary teachers in classrooms are provided.

\section{Current Research}

The Organisation for Economic Co-operation and Development (OECD, 2015) published a report, Students, Computers and Learning: Making the Connection, presenting an "internationally comparative analysis of the digital skills that students have acquired, and of the learning environments designed to develop these skills" (p.3). This study was informed by an analysis of 2012 OECD Programme for International Student Assessment (PISA) data. Herein lies a problem that forms the foundation of the argument presented in this paper. The developments in mobile technologies and the increased uptake of these devices in many schools since 2012 result in this data being outdated by the time of its publication. The lag between research and dissemination of findings often takes a period of at least two years. The exponential rate of technological development means that if and when the findings of research reaches teaching practitioners the tools available to teachers have evolved and the research may no longer be relevant nor appropriate.

The OECD (2015) report also claims that students who use computers (desktops, laptops or tablets) very frequently at school do worse in most learning outcomes than students who use them moderately. They also report that there are no "appreciable improvements in reading, mathematics, or science in the countries that had invested heavily in ICT for education" (p.3). These findings imply that in 2012, a time when mobile technologies were being introduced in classrooms all over the world, there were issues and challenges in integrating ICT. This is of significant concern in 2016 for schools where the expectations for technology integration continue to rise and more specifically, in mathematics classrooms, where teachers find it more challenging to maximize the potential of the affordances of mobile technologies in creative, student-centred ways than in other subject areas (Attard, 2013a).

\section{Tablets and the Primary Mathematics Classroom}

The range of flexible and ubiquitous mobile devices in contemporary classrooms are fast becoming the standard learning tools replacing the once prominent desktop computer (Meletiou-Mavrotheris, Mavrou, \& Paparistodemou, 2015). An illustration of this phenomenon can be seen in the increase in popularity of computer tablets. The iPad, released by Apple in 2011, has quickly become one of the most popular devices in schools alongside smartphones and other mobile devices. The relatively low cost and the vast range of affordances offered by 
tablets has made them attractive to schools. However, because of the quick take up of these devices, when they were first introduced teachers were expected to effectively incorporate them into their practices with little or no professional development. This was of particular concern in the area of mathematics as teachers were prone to using the devices in ways that reflected a traditional, drill and practice approach to learning due to the overwhelming number of applications (apps) available on the devices (Attard, 2015).

Although research into the use of tablets is now emerging, schools are already beginning to change direction in relation to the purchase of devices, and rather than providing or prescribing a specific device for students, 'Bring Your Own Device' (BYOD) programs, where a range of devices and platforms are used and students provide their own devices, are gaining momentum (Cristol \& Gimbert, 2014; Hu \& Garimella, 2014). This change brings about further significant challenges for teachers, particularly in the area of mathematics, where many teachers find it challenging to design technology integrated tasks that move beyond requiring students to act as consumers, through the use of drill and practice (apps) that build fluency, to producing, authoring and problem solving through the use of more generic productivity apps (Attard, 2013a; Zhang, Trussell, Gallegos, \& Asam, 2015). Issues beginning to emerge in classrooms relate to the range of devices and operating platforms being used at any one time, and often, the disparity that develops when the number of devices brought to school is inconsistent from one day to the next.

Another significant issue arises in relation to the affordances offered by tablet technologies. The range of applications is so broad; teachers find it difficult to select appropriate apps to suit the needs of their students and to promote the learning and understanding of mathematical concepts. Larkin (2015), investigated a wide range of geometry apps and their potential to assist the development of geometry concepts and found most apps only promoted revision of already known concepts. The OECD (2015) claim that the building of conceptual understanding requires intensive teacher-student interactions, and often this is neglected due to the novelty of new technology and a lack of pedagogical knowledge (Attard, 2013a). The OECD claim "we have not yet become good enough at the kind of pedagogies that make the most of technology...adding 21 st century technology to 20th-century teaching practices will just dilute the effectiveness of teaching" (p.3). So how do teachers learn to use new technologies and adapt their pedagogies effectively in the teaching of primary mathematics? The following section describes some frameworks and models that are currently available. 


\section{Frameworks for Using Technology}

Koehler and Mishra (2009) describe technological pedagogical content knowledge (TPACK) as a framework for technology integration and teacher knowledge, incorporating technology into Shulman's construct of pedagogical content knowledge (PCK) (1986). They describe three components that lie at the heart of good teaching with technology: content, pedagogy, and technology. "The interactions between and among the three components, playing out differently across diverse contexts, account for the wide variations seen in the extent and quality of educational technology integration" (p. 62).

Although the TPACK framework is generic, McGrath, Karabas and Willis (2011) believe the level of TPACK teachers require differs from one subject to another and also depends on context. Guererro (2010) argues that when TPACK is applied to mathematics, the framework extends beyond ways in which to use a specific tool or device, to ways it can be used to improve teaching and learning. Guerrero situates TPACK in the mathematics classroom, proposing four components that characterise the framework:

Conception and use of technology: the ways in which a teacher is able to conceptualise the use of specific technologies to support teaching and learning mathematics.

Technology-based instruction: the teacher's ability to adapt pedagogy and recognise the need for flexibility in instruction that results from the use of technology.

Management: the range of issues relating to implementation of technology including maintaining student engagement and dealing with behaviour management, and on the technical side, dealing with the physical environment, hardware and software issues.

Depth and breadth of mathematics content: the teacher's knowledge base in relation to the mathematics content and a willingness to allow students to explore mathematical content that may arise as a result of students' investigations using technology.

Although TPACK can be useful in describing the types of knowledge teachers require to successfully integrate technology, it may not be helpful in assisting teachers in their day-today implementation of technology. It cannot be assumed that teachers will use new devices such as iPads in "pedagogically innovative and appropriate ways" (Herrington et al., 2008, p. 419) and Bennison and Goos (2010) believe teachers are less likely to embed new technologies 
within their practices if they have limited or no support in developing new approaches to teaching, time to think deeply about their practices, and limited opportunity for professional dialogue.

There are several frameworks and models designed more specifically for classroom use that have been developed to assist teachers in planning for the use of technology. Amongst them are the Technology Integration Matrix (TIM) (Florida Centre for Instructional Technology, 2015), and the SAMR model (Puentedura, 2006). Although the frameworks are presented in different formats, there are similarities. In particular, TIM and SAMR models highlight how a basic use of technology promotes teacher-directed learning, and more successful, creative use of technology promotes a more student-centred approach.

\section{The SAMR Model}

The SAMR model (Puentedura, 2006) represents a series of levels of "incremental technology integration within learning environments" (van Oostveen, Muirhead, \& Goodman, 2011, p. 82). Mathematics-based iPad examples of the SAMR model are represented in Table 1.

Table 1

The SAMR Model, iPads and Mathematics (Attard, 2015)

\begin{tabular}{|c|c|c|}
\hline & Level & Example \\
\hline \multirow[t]{2}{*}{ Transformation } & $\begin{array}{l}\text { Redefinition } \\
\text { iPads Allod for the creation of } \\
\text { new tasks that were previously } \\
\text { inconceivable }\end{array}$ & $\begin{array}{l}\text { Use of a range of apps that allows the } \\
\text { student to author his or her own work } \\
\text { and create something new as a result. }\end{array}$ \\
\hline & $\begin{array}{l}\text { Modification } \\
\text { iPad allows for significant task } \\
\text { redesign }\end{array}$ & $\begin{array}{l}\text { Use of an app that allows a student to } \\
\text { record verbal and written responses } \\
\text { simultaneously. }\end{array}$ \\
\hline \multirow[t]{2}{*}{ Enhancement } & $\begin{array}{l}\text { Augmentation } \\
\text { iPad acts as a direct tool } \\
\text { substitute with functional } \\
\text { improvement }\end{array}$ & $\begin{array}{l}\text { Use of a game-based app that requires } \\
\text { the student to answer a range of } \\
\text { questions, provides immediate feedback } \\
\text { and provides the students with some } \\
\text { choice relating to the level of challenge. }\end{array}$ \\
\hline & $\begin{array}{l}\text { Substitution } \\
\text { iPad acts as a direct tool } \\
\text { substitute with no functional } \\
\text { change }\end{array}$ & $\begin{array}{l}\text { Use of an app that simply requires the } \\
\text { student to answer a series of mathematics } \\
\text { questions and may provide feedback. }\end{array}$ \\
\hline
\end{tabular}


The SAMR model can be a useful tool for teachers when planning to use iPads in their classrooms. However, no framework is perfect. SAMR and TIM do not include specific examples of apps that promote the learning of specific mathematical concepts, the mathematical processes such as problem solving and mathematical communication, and do not consider student engagement, which will be considered next. An additional concern is that there is no guarantee teachers will access and apply frameworks such as these unless they are specifically linked to curriculum requirements.

\section{Students and Mobile Technologies in the Mathematics Classroom}

Tablet devices are often used in classrooms for the purpose of increasing student engagement with mathematics and in turn, improving learning outcomes (Aagaard, 2015). For the purpose of this paper, engagement is defined as a multidimensional construct that is the coming together of cognitive, operative, and affective domains and leading to students valuing and enjoying school mathematics and seeing connections between school mathematics and their lives beyond the classroom (Attard, 2013b). In two studies investigating the introduction of iPads into primary mathematics classrooms in Australia (Attard, 2013a; Attard \& Curry, 2012) the teachers and students found the use of iPads appeared to improve student engagement. After six months of using the iPads, the students reported that mathematics lessons were more 'fun'. However, some students in the Attard and Curry (2012) study were observed to be disengaged from the mathematics whilst still playing a game and interacting with the iPad. Clearly some students were operatively and affectively engaged but not engaged on a cognitive level possibly due to a mismatch between their ability and the given task. This issue directly relates to the management component of TPACK (Guerrero, 2010) and perhaps is something that would have improved over time and through teacher experience and research-informed professional development.

The use of iPads in each of the studies above appeared to have begun to bridge the 'digital divide' (Selwyn, Potter, \& Cranmer, 2009), addressing the disparity between the students' use of digital technologies at home and at school. In the Attard (2013a) study, the teachers reported that their students had downloaded and used mathematics-based apps at home that had featured in their mathematics lessons. This bridge between school and home mathematics may have contributed to the apparent increase in these students' engagement with mathematics. However, at the time these studies were conducted, the engagement factor may have been largely due to the novelty of the devices. In both studies it was found that the 
mathematics tasks were more aligned with substitution and augmentation levels of the SAMR model and may not have promoted the cognitive challenge required for sustained student engagement.

A study conducted by Ingram, Williamson-Leadley, and Pratt (2015) on the use of a Show and Tell app used a framework of student engagement and effective pedagogy to analyse data collected from participating teachers. Ingram et al. add strength to the argument in this paper by stating the need to focus on mathematics rather than the technology means "that it is important to consider what effective pedagogy in mathematics involves" (p.4), particularly in relation to selecting appropriate apps for use with mobile technologies.

Significant improvements in student engagement relating to the use of technology and mathematics were reported by Mulqueeny, Kostyik, Baker and Ocumpaugh (2015). However, this study focused on the use of a specific software system, Reasoning Mind, and a carefully designed blended learning approach rather than a focus on the devices used. The approach taken in the Mulqueeny et al. study incorporated game-based activities that were adapted to suit individual learners' needs and included assessment that enabled the researchers to measure improvements in student learning. The success of this particular study has implications for the focus of future research into mobile technologies and suggests more emphasis on the overall design of the learning experiences and the related pedagogies would be beneficial to teachers and would assist in identifying improvements in learning outcomes. Although it is clear that the use of contemporary technologies has the potential to improve engagement and learning, the challenge of device distraction will now be briefly explored.

\section{Challenges Relating to ICT}

Students of all ages are now more connected to the Internet and unlimited information than ever before (Taneja, Fiore, \& Fischer, 2015). Although the ubiquitous access of ICT has the potential to improve student engagement, it can also challenge educational practice (Aagaard, 2015). Studies are beginning to emerge that show students often use technologies for off-task activity and multitasking, leading to distraction (for example see Ravizza, Hambrick, \& Fenn, 2014; Attard, 2013a). “...just as laptops and tablets open up the possibility of bringing the world into the classroom, they also constitute a backdoor through which students may escape". Student on-task and off-task technology related behaviour during mathematics lessons is directly related to task design and the pedagogical practices of the teachers, and strengthens the argument for research that will assist practitioners in a timely manner. 


\section{Future Research to Assist Teachers}

The purpose of this paper was to question whether current research on the use of technology to teach mathematics in primary classrooms is of assistance to teachers. The increased popularity of mobile technologies such as the iPad was used as an example of how teachers are expected to use emerging devices and their software applications effectively prior to the dissemination of research findings that provide exemplars of best practice.

Many of the emerging research findings pertaining to the use of technology in mathematics classrooms are drawn from small studies that are often not generalisable on a larger scale. There appears to be a lack of research into the ways technology can be utilised to support conceptual understanding rather than simply improving fluency. The exponential rate of technology development and the slow rate by which research findings are disseminated means that teachers would benefit from future research that is focused on preparing them to use any technology, rather than always working retrospectively to explore the use of devices that have already emerged.

Examples of potential research questions are as follows:

- How can pre-service teachers be better prepared to use emerging technologies in the primary mathematics classroom?

- What are student perceptions pertaining to the amount of technology used and they ways in which it is used in the primary mathematics classroom?

- What does effective use of ICT incorporating mobile technologies look like in contemporary primary mathematics classrooms?

- How can we develop a practical framework for teachers beyond TPACK and SAMR that incorporates pedagogy, content and technology skills to prepare them to effectively teach mathematics with emerging technologies?

Further, sustained research that identifies successful practices with technology is required as a matter of urgency, as is the importance of timely dissemination. Larger scale research that develops new frameworks or specifically applies existing frameworks such as TPACK and the SAMR model to a variety of technologies available in primary mathematics classrooms would also be of great benefit to practitioners. Finally, research into effective professional learning models that incorporate the use of technology and the teaching of mathematics is of vital importance, as is the development of professional learning networks where teachers are able to share experiences and practices relating to technology integration. 


\section{References}

Aagaard, J. (2015). Drawn to distraction: A qualitative study of off-task use of educational technology. Computers \& Education, 87, 90-97.

Attard, C. (2015). Introducing iPads into Primary Mathematics Classrooms: Teachers' Experiences and Pedagogies. In M. Meletiou-Mavrotheris, K. Mavrou \& E. Paparistodemou (Eds.), Integrating Touch Enabled and Mobile Devices into Contemporary Mathematics Education (pp. 197-217). Hershey, PA: IGI Global.

Attard, C. (2013a). Introducing iPads into Primary Mathematics Pedagogies: An Exploration of Two Teachers' Experiences. Paper presented at the Mathematics education: Yesterday, today and tomorrow (Proceedings of the 36th Annual conference of the Mathematics Education Research Group of Australasia, pp.58-65). Melbourne: MERGA

Attard, C. (2013b). "If I had to pick any subject, it wouldn't be maths": Foundations for engagement with mathematics during the middle years. Mathematics Education Research Journal, 25(4), 569-587.

Attard, C, \& Curry, C. (2012). Exploring the use of iPads to engage young students with mathematics. Paper presented at the Mathematics education: Expanding horizons. Proceedings of the 35th annual conference of the Mathematics Education Research Group of Australasia. (MERGA-35) (pp.75-82). Singapore: MERGA.

Bennison, A, \& Goos, M. (2010). Learning to teach mathematics with technology: A survey of professional development needs, experiences and impacts. Mathematics Education Research Journal, 22(1), 31-56.

Cristol, D., \& Gimbert, B. (2014). Academic achievement in BYOD classrooms. Journal of Applied Learning Technology, 4(1), 24-30.

Florida Center for Instructional Technology. (2005). Technology Integration Model. Retrieved 15 September, 2014, 2014, from http://fcit.usf.edu/matrix/matrix.php

Guerrero, S. (2010). Technological pedagogical content knowledge in the mathematics classroom. Journal of Digital Learning in Teacher Education, 26(4), 132-139.

Herrington, J, Mantei, J, Herrington, A, Olney, I, \& Ferry, B. (2008). New technologies, new pedagogies: Mobile technologies and new ways of teaching and learning. Paper presented at the Annual Australian Society for Computers in Learning in Tertiary Education Conference, Melbourne.

Hu, H., \& Garimella, U. (2014). iPads for STEM teachers: A case study on perceived usefulness, perceived proficiency, intention to adopt, and integration in K-12 instruction. Journal of Educational Technology Development and Change, 7(1), 49-66.

Ingram, N., Williamson-Leadley, S., \& Pratt, J. (2015). Showing and telling: Using tablet technology to engage students in mathematics. Mathematics Education Research Journal, 1-25, doi:10.1007/s13394-015-0162-y

Koehler, M. J., \& Mishra, P. (2009). What is technological pedagogical content knowledge? Contemporary Issues in Technoogy and Teacher Education, 9(1), 60-70.

Larkin, K. (2015). The search for fidelity in geometry apps: An exercise in futility? In M. Marshman, V. Gieger, \& A. Bennison (Eds.) Mathematics Education in the Margins (Proceedings of the 38 ${ }^{\text {th }}$ Annual Conference of the Mathematics Education Research Group of Australasia, pp.341-348). Sunshine Coast: MERGA.

McGrath, J, Karabas, G, \& Willis, J. (2011). From TPACK concept to TPACK practice: An analysis of the suitability and usefulness of the concept as a guide in the real world of teacher development. International Journal of Technology in Teaching and Learning, $7(1), 1-23$. 
Meletiou-Mavrotheris, M., Mavrou, K., \& Paparistodemou, E. (2015) Preface. Integrating touch-enabled and mobile devices into contemporary mathematics education. (pp. xxxxvii). Hershey, PA: IGI Global

Mulqueeny, K., Kostyuk, V., Baker, R., \& Ocumpaugh, J. (2015) Incorporating effective elearning principles to improve student engagement in middle-school mathematics. International Journal of STEM Education, 2(1), 1-14.

OECD (2015), Students, Computers and Learning: Making the Connection, PISA, OECD Publishing, Paris. DOI: http://dx.doi.org/10.1787/9789264239555-en

Orlando, J., \& Attard, C. (2015). Digital natives come of age: the reality of today's early career teachers using mobile devices to teach mathematics. Mathematics Education Research Journal, 1-15. doi: 10.1007/s13394-015-0159-6

Prensky, M. (2001). Digital natives, digital immigrants. On the Horizon, 9(5), 1-6.

Puentedura, R. (2006). SAMR. Retrieved July 16, 2013, from http://www.hippasus.com

Ravizza, S., Hambrick, D., \& Fennm K. (2014). Non-academic internet use in the classroom is negatively related to classroom learning regardless of intellectual ability. Computers \& Education, 78, 109-114.

Selwyn, N., Potter, J., \& Cranmer, S. (2009). Primary pupils' use of information and communication technologies at school and home. British Journal of Educational Technology, 40(5), 919-932.

Shulman, L. S. (1986). Those who understand: Knowledge growth in teaching. American Educational Research Journal, 15(2), 4-14.

Taneja, A, Fiore, V., \& Fischer, B. (2015). Cyber-slacking in the classroom: Potential for digital distraction in the new age. Computers \& Education, 82, 141-151.

van Oostveen, R, Muirhead, William, \& Goodman, William M. (2011). Tablet PCs and reconceptualizing learning with technology: a case study in higher education. Interactive Technology and Smart Education, 8(2), 78-93. doi: http://dx.doi.org/10.1108/17415651111141803

Zhang, M., Trussell R., Gallegos, B., \& Asam, R. (2015). Using math apps for improving student learning: An exploratory study in an inclusive fourth grade classroom. Tech Trends, 59(2), 32-39. 